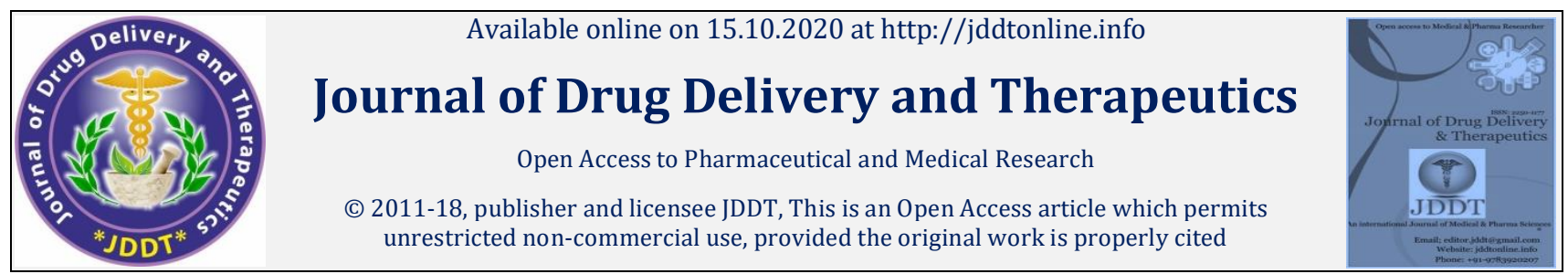

Open Access

Research Article

\title{
Evaluation of the curative role, Anti-inflammatory and anti-oxidative activity of some dietary spices on carrageenan induced paw edema in albino Wistar rats
}

\author{
Bouaoud Khaoula, Menadi Noreddine, Zairi Mohammed, Bouazza Sofiane, Bekhadda Hadjer, Meraou Asmaa, \\ Benali Amina, Bensaid Ilies, Mai Hicham, Benali Mahmoud, Demmouche Abbassia*
}

Biotoxicology laboratory, Department of Biology, Faculty of Natural Sciences and life-Djillali Liabes University of Sidi Bel Abbes, Algeria

\begin{abstract}
Background: Inflammation is a response of the immune system, guarding the individual against infection. It is a major burning problem worldwide and billions of individuals are affected. Some of the spices used daily in Algerian cuisine have been known to poss ess major antiinflammatory effects. Turmeric, red pepper, ginger, cinnamon and cumin etc. are a few of the wide spectrum of spices used in Algeria.

The aim of the study was to investigate the antiinflammatory effect and anti actvity of some dietary spices in carrageenan induced models of inflammation on Wistar rats.

Methods: Albino wistar rats were divided into four groups. Inflammation was induced on the animal by injecting the right hand paw with carrageenan $(0.1 \mathrm{ml}$ of $1 \%)$. Group 1 was fed with food and water and treated with carrageenan (control) whereas group 2 and 3 treated with different doses (100 and $200 \mathrm{mg} / \mathrm{kg} / \mathrm{bw}$ ) of aqueous extract of some dietary spices with carrageenan, respectively. Group 4 treated with standard drug diclofenac sodium (10 mg/kg b.w., reference drug for inflammation), once for $24 \mathrm{hrs}$.

Results: The content of total phenolic was $137.2 \pm 21.6 \mathrm{mg} / \mathrm{g}$ and flavonoids $122.3 \pm 5.8 \mathrm{mg} / \mathrm{g}$. After $60,120,180,240$ and $300 \mathrm{~min}$, the data indicate that some dietary spices 100 and $200 \mathrm{mg} / \mathrm{kg}$ was significantly effective reducing paw edema volumes induced by carrageenan compared to control $(\mathrm{p}<0.01)$. The levels of serum pro-inflammatory white blood cells, neutrophile, lymphocyte, monocyte, eosinophile, total protein and protein c reactive and total cephalin KADIN and platelts in the control group were significantly increased by carrageenan injection compared with the normal group. The rats pretreated with some spices 100 and $200 \mathrm{mg} / \mathrm{kg}$ had significantly lower levels of pro-inflammatory to compare control group. The paw edema in carrageenan-induced rats was considerably reduced by treating with 100 and 200 mg/kg aqueous extract of some dietary spices when compared to the untreated rats $(\mathrm{p}<0.001)$.
\end{abstract}

Conclusion : The present results clearly demonstarted that carrageenan significantly increased paw edema whereas some dietary treated rats significantly decreased the paw edema. The study underlines the importance of some of the frequently used spices (Turmeric, red pepper, ginger, cinnamon and cumin) in the treatment of inflammation.

Keywords: inflammation; herbal medicine; paw edema; spices, Algeria

Article Info: Received 13 Aug 2020; $\quad$ Review Completed 17 Sep 2020; $\quad$ Accepted 29 Sep 2020; $\quad$ Available online 15 Oct 2020

Cite this article as:

Bouaoud K, Menadi N, Zairi M, Bouazza S, Bekhadda H, Meraou A, Benali A, Bensaid I, Mai H, Benali M, Demmouche A, Evaluation of the curative role, Anti-inflammatory and anti-oxidative activity of some dietary spices on carrageenan induced paw edema in albino Wistar rats, Journal of Drug Delivery and Therapeutics. 2020; 10(5-s):90-96 http://dx.doi.org/10.22270/jddt.v10i5-s.4477

*Address for Correspondence:

Demmouche Abbassia, Professor in Biology, Faculty of Naturel Science and Life-Djillali Liabes. University Sidi Bel Abbes. Algeria

\section{INTRODUCTION}

Inflammation is a major burning problem worldwide and billions of individuals are affected. It is well known, the herbal formulations had been used preventive and therapeutic medicine for a long time. Healing properties of medicinal plants were noted for ancient medical books. In traditional medicine, plants have long been used as alternative treatments for a wide range of diseases, including inflammatory processes of diverse origins, and have provided symptomatic relief comparable to that obtained from allopathic medicines $\mathbf{1}, \mathbf{2}$.

Spices and herbs are usually whole plants or parts of plants that are used for flavouring and preservation of food all over the world. The people of the Algeria subcontinent exploit their rich biodiversity and use various plants or their parts as spices for daily cooking and preservation of food from 
time immemorial. These spices also have medicinal properties that have been underlined in the traditional systems of medicine like red pepper, ginger, cinnamon, etc.

Various plants/ plant parts are used as spices in Algeria. Turmeric, red pepper, ginger, cinnamon and cumin etc. are a few of the wide spectrum of spices used in Algeria. Most of the spices have been studied for their various pharmacological properties. Cumin seed is known for its anti-microbial, antidiabetic, anti-oxidant, anti-tumorigenic properties alongside its gastroprotective, hepatoprotective and cardioprotective properties ${ }^{3}$.

There are various mechanisms to an inflammatory reaction, which can contribute to the associated symptoms and tissue injury. Edema, granuloma formation, and leukocyte infiltration signify such components of inflammation.

The carrageenan (Carr) induced edema, as an inflammation model, is usually used to assess the contribution of natural products to resist the biochemical changes associated with acute inflammation. When Carr is injected, acute inflammation with edema appears, along with a production of free radicals as well as a release of inflammatory mediators 4 . The anti-inflammatory effect of some of the medicinal plants/herbs have been validated and few others disproved. The present study focuses on the antiinflammatory and anti-activity potential of a few of the spices used in Algeria.

\section{METHODS}

\section{Plant material}

The various spices used in the Algerian household were randomly selected after consultation with the persons of the household. Turmeric, red pepper, ginger, cinnamon and cumin were collected during March-April 2019 from SBA vegetable market Algeia. The plant material was taxonomically identified by a botanist.

\section{Test for flavonoids}

To $1 \mathrm{ml}$ of the extract, $5 \mathrm{ml}$ of dilute ammonia is added. In addition, of $1 \mathrm{ml}$ concentrated $\mathrm{H} 2 \mathrm{SO} 4$ a yellow color solution is temporarily produced which indicate the present of flavonoid. As a confirm test for flavonoid, a few drops of $1 \%$ aluminum solution is added to the plant extract and formation of a permanent yellow color solution indicates the presence of flavonoid. Test for saponins To $1 \mathrm{ml}$ of extract, 1 $\mathrm{ml}$ of distilled water was added and shaken vigorously; a stable permanent form will develop indicating its presence. The result was positive for the test 5 .

\section{Test for phenols}

A portion of the extract of the samples was diluted with distilled water in a ratio 1:4. Few drops of $10 \%$ ferric chloride solution were added. The appearance of green solution indicates the presence of phenol, which was present. 6.

\section{Experimental animals}

Female rats of weighing 150-200 g were procured from the Pasteur Institute (Algiers, Algeria) and were housed in a clean polypropylene cages and maintained under standard laboratory conditions (temperature $25 \pm 2{ }^{\circ} \mathrm{C}$ with dark/light cycle $12 / 12 \mathrm{hrs}$ )

They were fed with standard pellet diet and water ad libitum. The animals were acclimatized to laboratory conditions for 10 days before experiment. All experimental procedures described were reviewed and approved by the Institutional Animal Ethics Committee.

\subsubsection{Model of Carrageenan-Induced Paw Edema.}

Lambda carrageenan was purchased from Sigma Chemical Company (St. Louis, USA). It was used to induce paw edema. $1 \% \mathrm{w} / \mathrm{v}$ carrageenan was prepared by dissolving $1 \mathrm{mg}$ of carrageenan in $100 \mathrm{~mL}$ of normal saline.

The antiinflammatory activity was evaluated by the method of Carrinduced edema in the subplantar region of the right hind paw of the rats. Edema was induced by an injection of $0.1 \mathrm{~mL}$ of $1 \%$ freshly prepared suspension of carrageenan 7 .

The immune system recognizes damaged or infected cells, pathogens, and begins the healing processitself. But, if the processis not regulated, or the offending agent persists, the intended protective process tends to be destructive 8 .

\section{Statistical analysis :}

The statistical analysis is performed with IBM SPSS v 26 software, The graphical representation is illustrated with Microsoft Excel 2019, The results are expressed as mean and standard deviation. The comparison between the experimental groups is carried out with the one way ANOVA test, followed if significant by the Tukey post hoc test, Welch test or kruskal-Wallist test, The significance level is 0.05 .

\section{RESULTS}

Preliminarily, the presence of the phytochemicals was assessed to identify the potential constituents present in the extract. The aqueous extract of some diatery spices was also tested for the presence of phytochemicals by the methods described in the materials and methods section. Table 2 and figure 1, 2 show the presence of phytochemical constituents such as flavonoids and phenol in the aqueous extract of spices.

\section{Total phenolic and flavonoids contents}

The flavonoid contents of the extract in term of rutin equivalent (Standard curve equation: $y=0,153 x+0,005, R^{2}$ $=0,984 \mathrm{~J}$, and the flavonoid content in the extract of some diatery species was $\mathbf{1 2 2 . 3} \pm \mathbf{5 . 8} \mathrm{mg} / \mathrm{g}$. The total content of phenolic compoundsshowed as Gallic acid equivalent (Standard curve equation: $\mathrm{y}=0,239 \mathrm{x}+0,155, \mathrm{R}^{2}=0,997$ ), and the total phenolic compound was $137.2 \pm 21.6 \mathrm{mg} / \mathrm{g}$ in some diatery species.

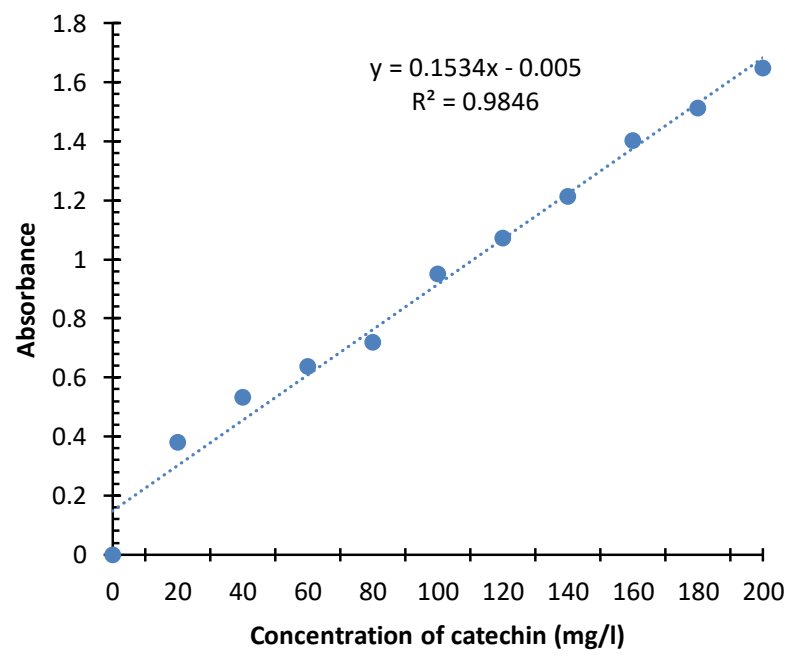

Figure 1: Standard curve of catechin 


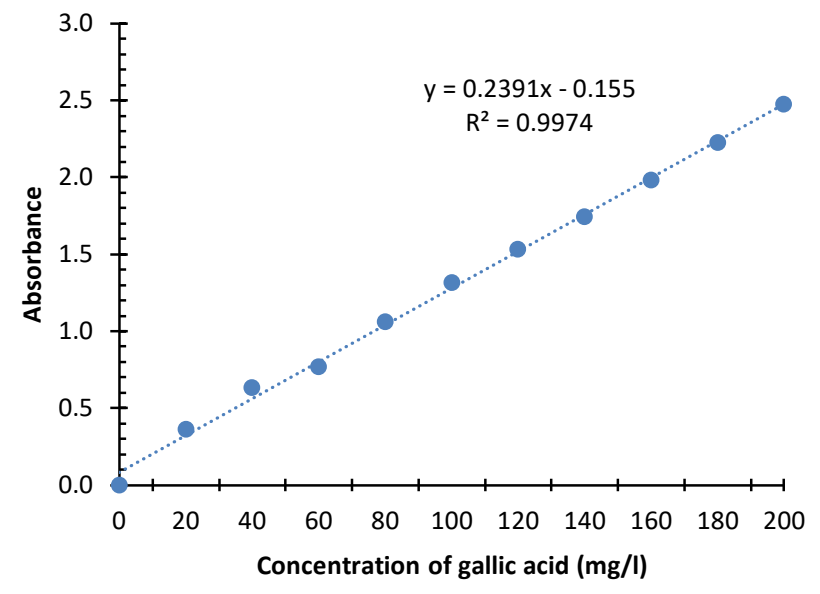

Figure 2: Standard curve of gallic acid

\section{Effect of some diatery spices on hind paw edema}

Therefore the present study is undertaken in an aim to screen the efficacy of anti-inflammatory potential of some diatery spices in experimental rats. In the present study, the acute inflammation was experimentally induced by Carrageenan.

The different doses of some diatery spices treated rats showed an inhibition of Carrageenan induced paw edema in all observed time intervals as compared to Carrageenan induced paw edema.

\section{Anti-inflammatory test}

In subplantar injection of carrageenan induced a timedependent increase in paw edema consisting of a relatively rapid early phase (up to 3 hour), ( $p=0,003$ ), and followed by late phase (4-5 hour). In the control group, the volume of hind paw edema was significantly increased by carrageenan injection in both phases and it reached peak levels at the late phase. Pretreatment of rats with some diatery spices $(100$ and $200 \mathrm{mg} / \mathrm{kg})$ and DICLOFENAC $(10 \mathrm{mg} / \mathrm{kg})$ administered by oral resulted in inhibition $(* * *<0,001))$ of carrageenaninduced hind paw edema in both phases (FIGURE 3, 4).

Aqueous extract of spices at a dose of $200 \mathrm{mg} / \mathrm{kg}$ exhibited significant antiinflammatory activity in carrageenan induced rat paw oedema model (Figure 5).

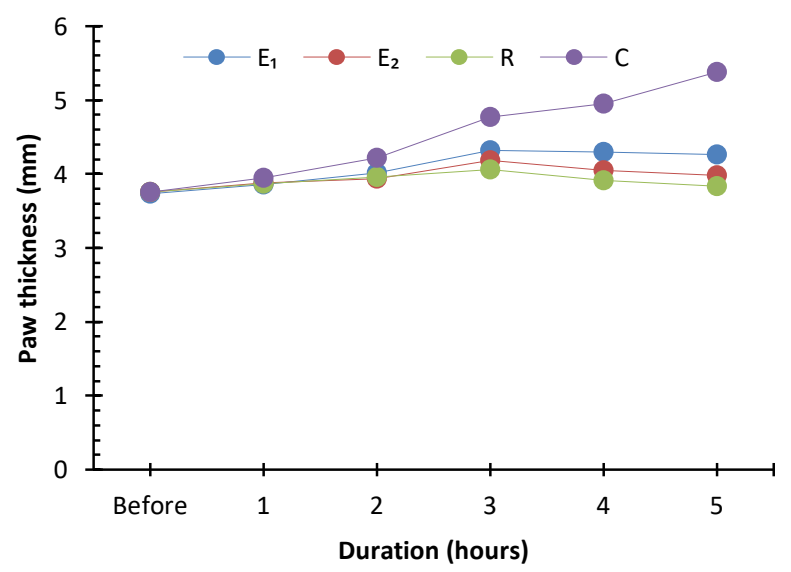

C: control; $\mathbf{E}_{1}$ :extract of the mixture of spices $(100 \mathrm{mg} / \mathrm{kg})$;

$\mathbf{E}_{2}$ : extract of the mixture of spices $(200 \mathrm{mg} / \mathrm{kg}) ; \mathbf{R}$ :

Diclofenac Sodium (10 mg/kg).

Figure 3: Paw thickness evolution during five hours

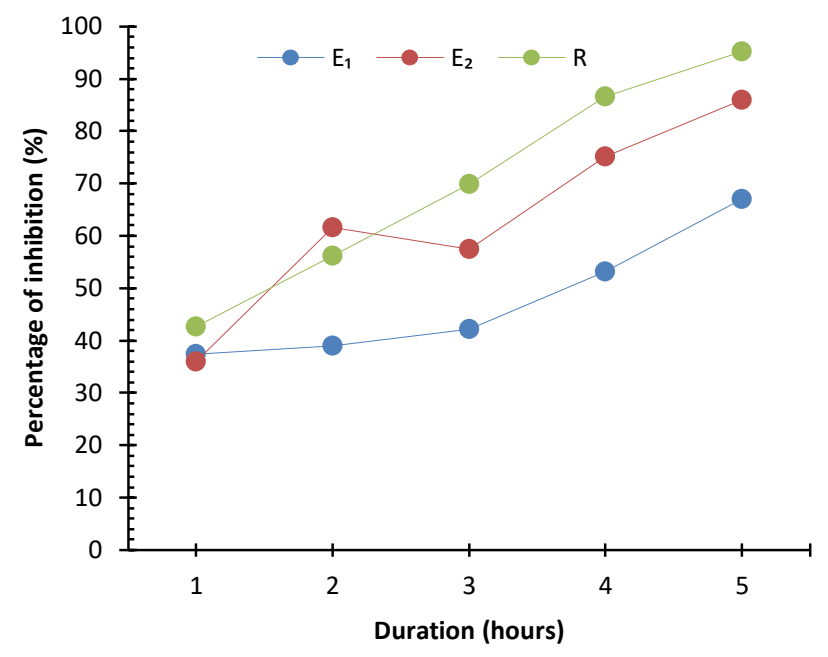

E1: extract of the mixture of spices $(100 \mathrm{mg} / \mathrm{kg}) ; \mathbf{E}_{2}$ : extract of the mixture of spices $(200 \mathrm{mg} / \mathrm{kg}$ ); R: Diclofenac Sodium (10 mg/kg).

Figure 4: Percentage of inhibition variation during five hours

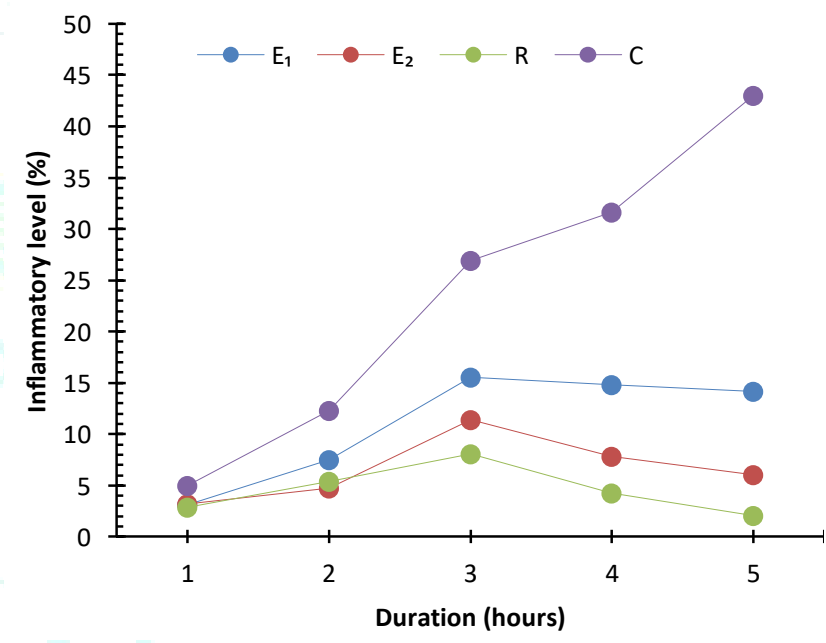

C: control; E1: extract of the mixture of spices $(100 \mathrm{mg} / \mathrm{kg})$; $\mathbf{E}_{2}$ : extract of the mixture of spices $(200 \mathrm{mg} / \mathrm{kg}) ; \mathbf{R}$ : Diclofenac Sodium (10 mg/kg).

Figure 5: Inflammatory level variation during five hours

The levels of serum pro-inflammatory white blood cells, neutrophile, lymphocyte, monocyte, eosinophile, total protein and protein c reactive and total cephalin KADIN and platelts in the control group were significantly increased by carrageenan injection compared with the normal group. The rats pretreated with some spices 100 and $200 \mathrm{mg} / \mathrm{kg}$ had significantly lower levels of pro-inflammatory to compare control group (Figure 6-15)

Therefore, the oral administration of some spices $200 \mathrm{mg} / \mathrm{kg}$ to pretreated group resulted in significant $\left({ }^{* *} \mathrm{p}<0.01\right)$ increase of red blood cells and hemoglobin and fibrinogen compared with the control group (Figure 16-18). 


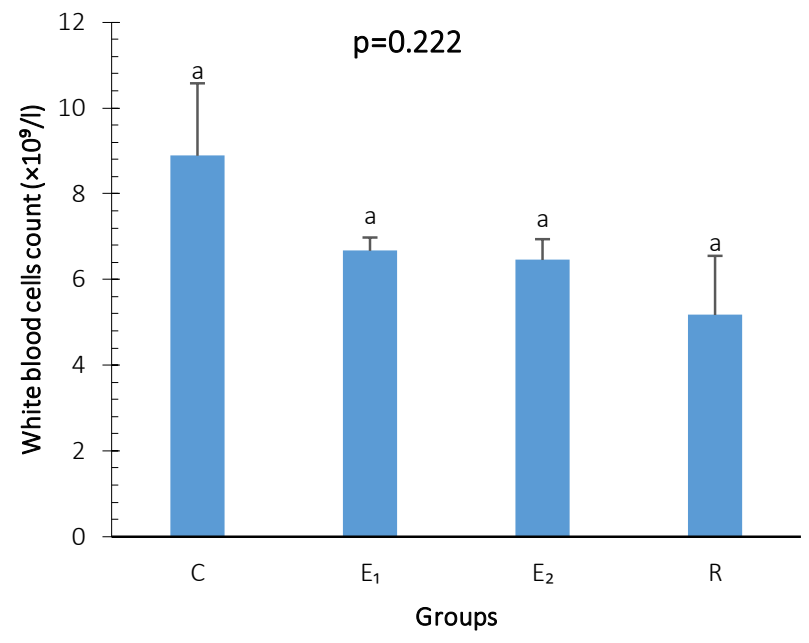

Figure 6: Variation of white blood cells count between the diferent groups

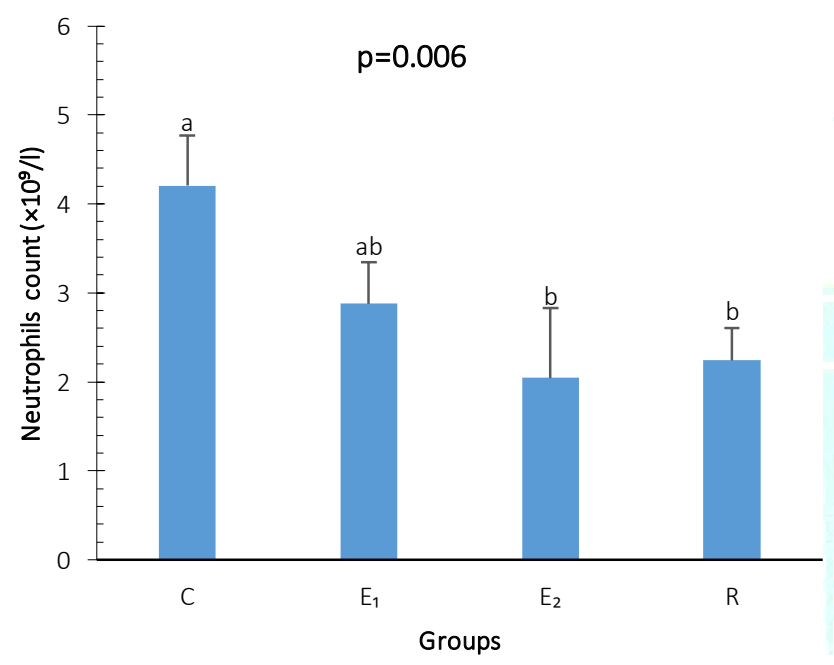

Figure 7: Variation of neutrophils count between the diferent groups

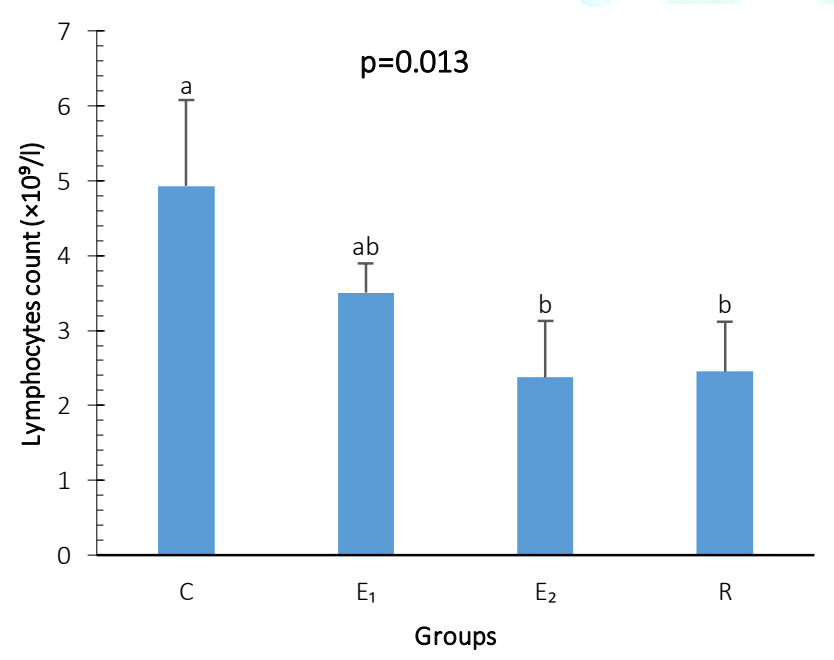

Figure 8: Variation of lymphocytes count between the diferent groups

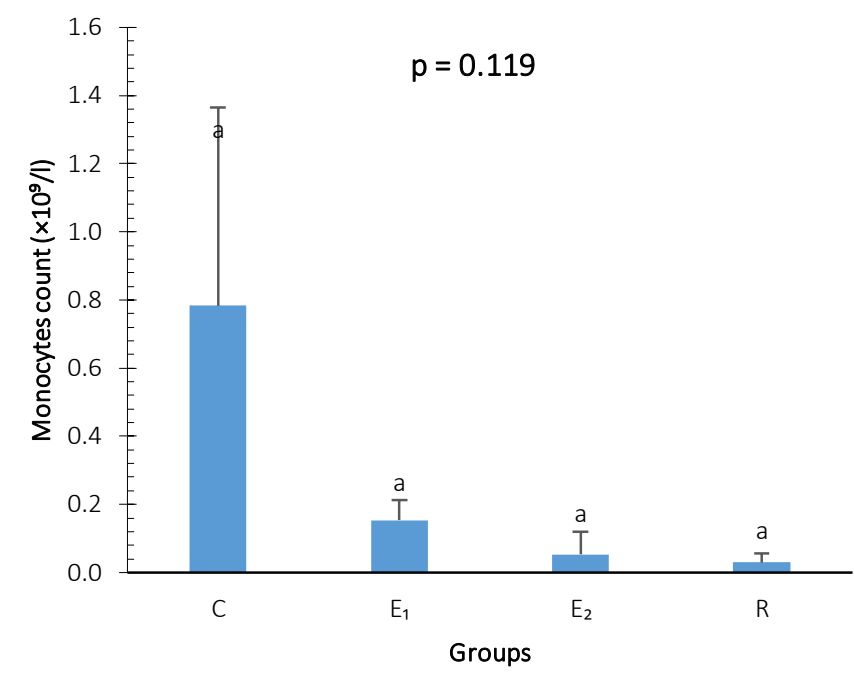

Figure 9: Variation of monocytes cells count between the diferent groups

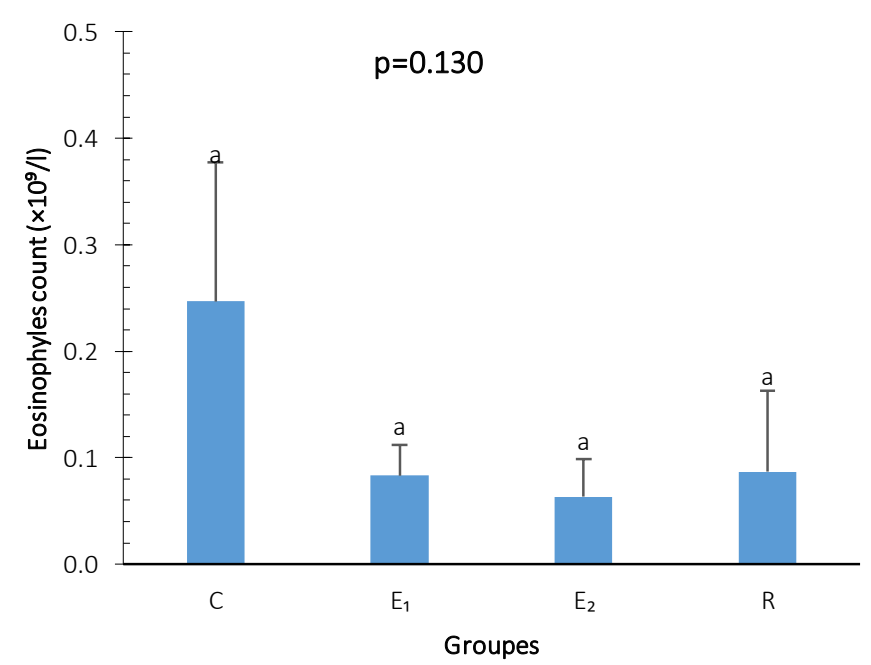

Figure 10: Variation of eosinophiles count between the diferent groups

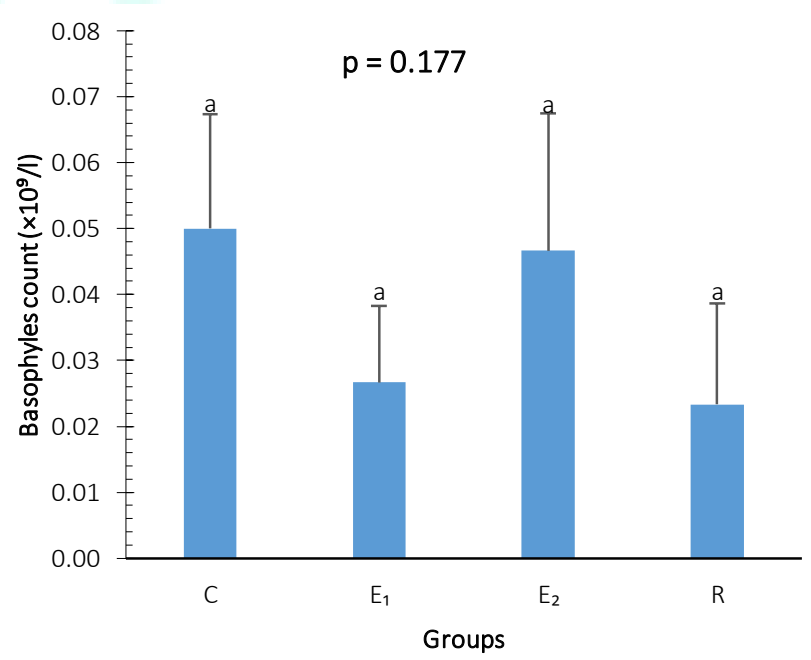

Figure 11: Variation of bosophyles count between the diferent groups 


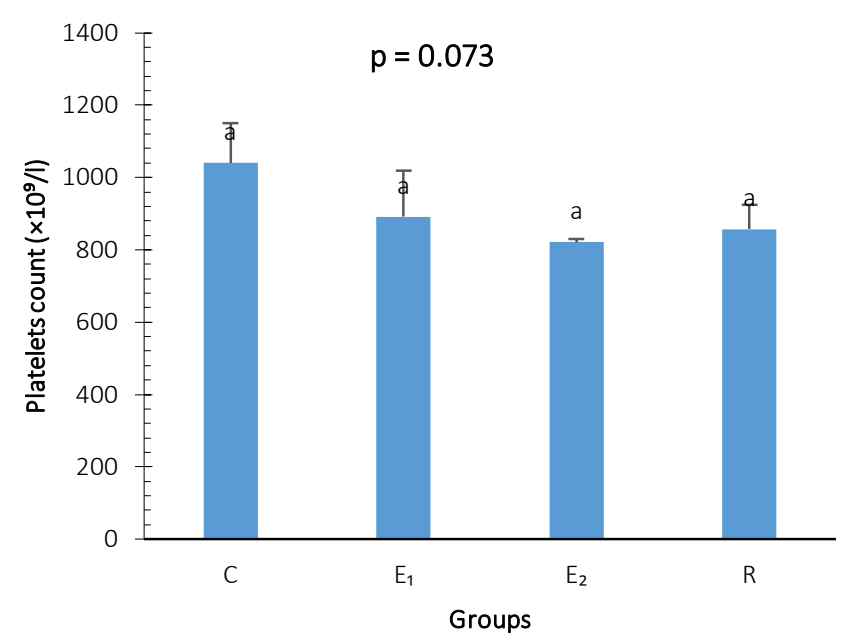

Figure 12: Variation of platetets count between the diferent groups

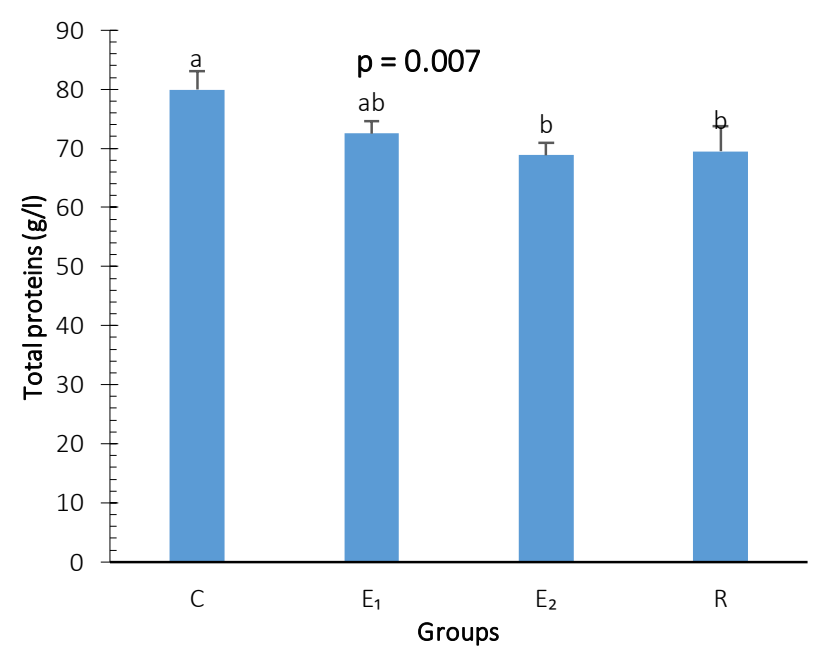

Figure 13: Variation of total proteins between the diferent groups

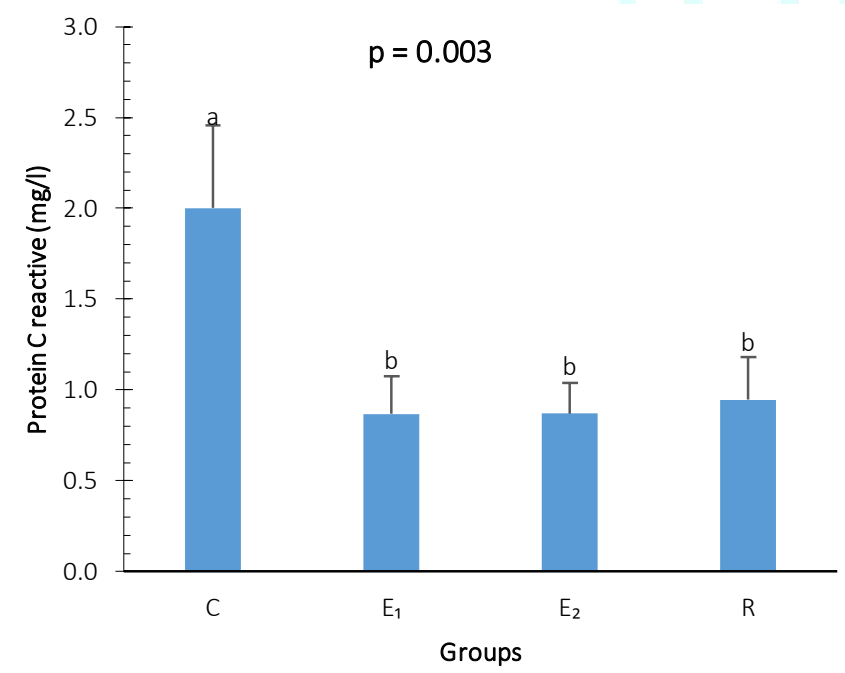

Figure 14: Variation of protein Creactive between the diferent groups

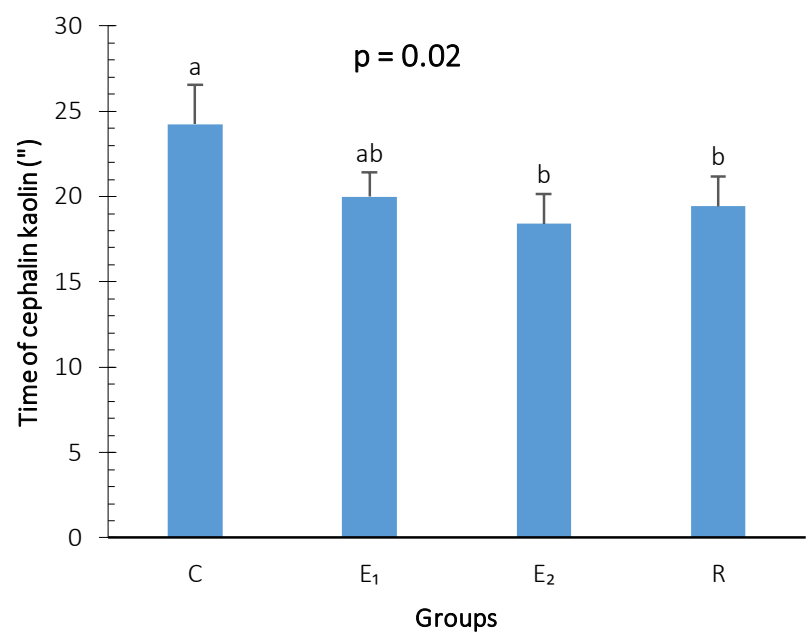

Figure 15: Variation of cephalin kadin between the diferent groups

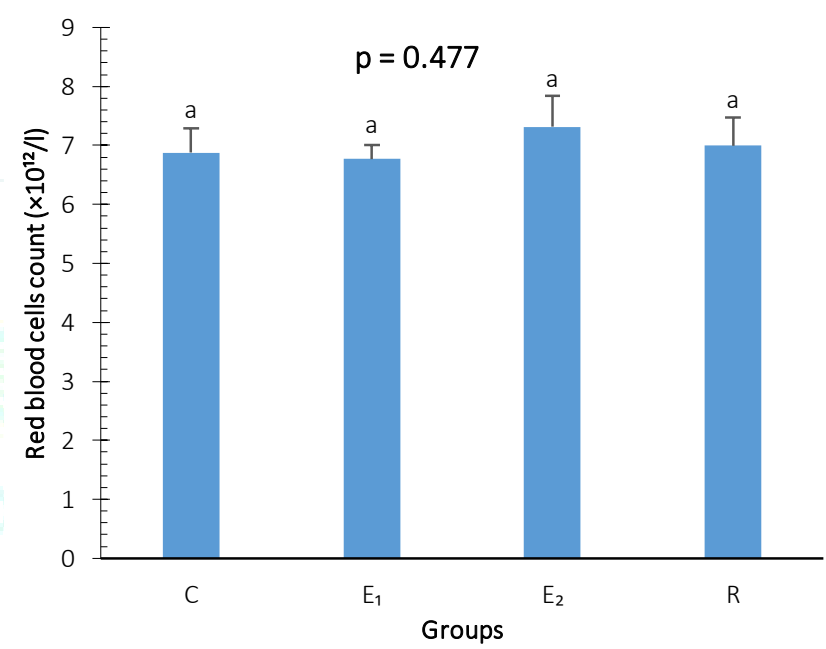

Figure 16: Variation of red blood cells count between the diferent groups

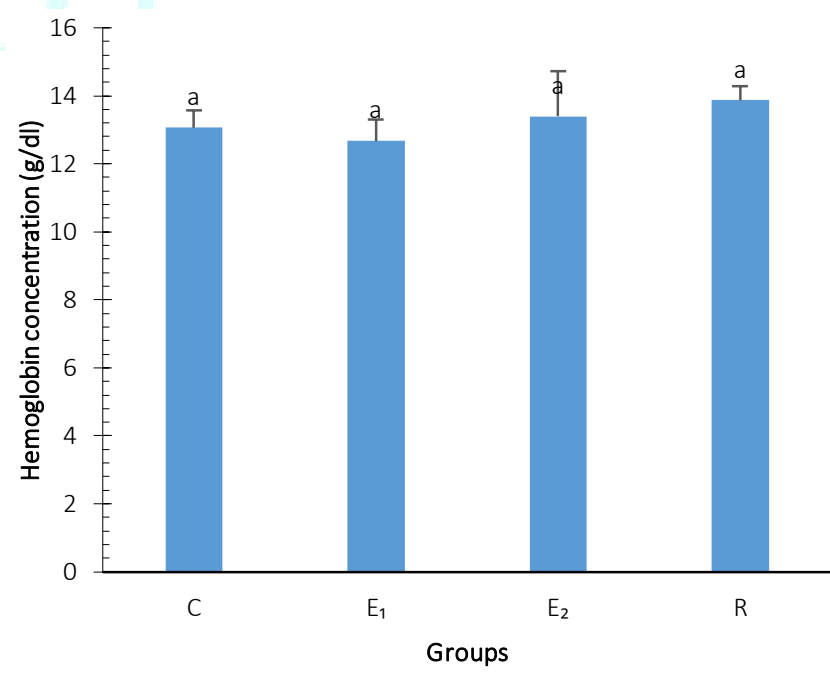

Figure 17: Variation of hemoglobin concentration between the diferent groups 


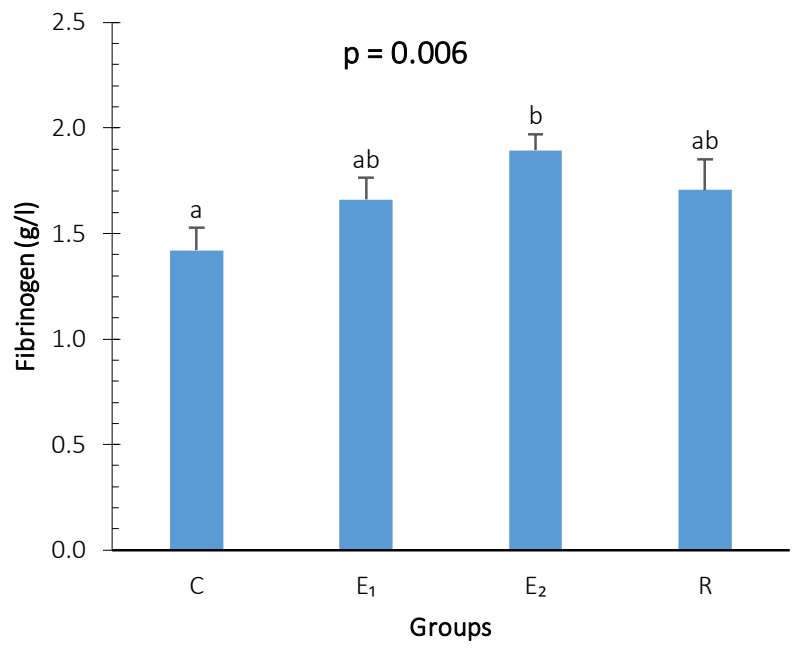

Figure 18: Variation of fibrinogen between the diferent groups

\section{DISCUSSION}

A great number of spices possess anti-inflammatory activity though some like mustard is known for their proinflammatory activity too.

The anti- anti-inflammatory effects of some of the medicinal plants have been validated and others disproved $\mathbf{1 0}$.

This investigation was the first experimental study designed to evaluate some diatery spices (combination of Turmeric, red pepper, ginger, cinnamon and cumin) would have antiinflammatory effect on carrageenan a. From the results of the study, the some spices had sufficient potential to treat inflammatory disorders by reducing proinflammatory protein c reactive. The present study showed that the carrageenan-induced inflammation an elevation in the levels of serum neutophil and eosinophil cells with hind paw edema. These observed results are the major symptoms of inflammatory conditions 11-12.

In the current study, it was observed that both phases of the carrageenan-induced hind paw edema were significantly reduced by pretreatment of rats with some spices.

The result of this study suggests that aqueous extract of some spices (Turmeric, red pepper, ginger, cinnamon and cumin ) has antiinflammatory effect comparable to those of the standard drugs such as DICLOFENAC. Carrageenaninduced inflammatory process is believed to be biphasic ${ }^{13}$.

This observation is in line with a similar study carried out by Panahi et al., 2016 which the Curcumin, isolated from turmeric, has been widely studied for its anti-inflammatory activity. In persons with metabolic syndrome, treatment with curcumin inhibited inflammatory mediators and cytokines like tumour necrosis factor-alpha (TNF $\alpha$ ), tumour growth factor-beta (TGF $\beta$ ), interleukin 6 (IL-6) and monocyte chemoattractant protein 1(MCP-1) 14. Edwards et al.(2017) referred curcumin as a pro-drug which on oxidative activation inhibited p65 subunit of nuclear factor kappa beta (NF- $\kappa \beta)$ and inhibitor kappa beta kinase (IKK $\beta$ ), the enzymes responsible for activation of NF- $\kappa \beta$ and its subsequent translocation to the nucleus to activate the proinflammatory mediators. The studies indicate that more than one component of turmeric is potent enough to be developed into an antiinflammatory drug 15.

Also, Both the extracts caused a significant reduction in paw edema induced by carrageenan in Wistar rats. The ethanolic extract was more effective as an analgesic as it reduced the number of writhes (in acetic acid induced writhing) and increased response time (in Eddy's hot plate method) while the aqueous extract did not show changes in the latter method 16.

The aqueous extract of ginger inhibited carrageenin induced paw edema in Sprague Dawley rats at doses of $25-200 \mathrm{mg} / \mathrm{kg}$ b.w. It also inhibited the inflammatory markers like NO, PGE2, inflammatory cytokines like TNF- $\alpha$, IL-1 $\beta$, IL-6, IFN- $\gamma$, chemokines and increased the total antioxidant capacity as measured in inflammatory exudates obtained from carrageenan injected hind paws of rats. Significant histopathological changes from control group were observed in rats treated with $200 \mathrm{mg} / \mathrm{kg}$ b.w. ginger extract 17 .

Cuminaldehyde, one main component obtained from cumin, and its bioconverted molecules also inhibited COX-2 and lipoxygenase activity, another well known mediator of inflammation as studied by in-silico molecular docking method 18.

Besides its use as spice, Black pepper is also used as pesticides, insecticide and in perfumery. Traditionally they were used to treat menstrual problems, ear-nose-throat related problems, diarrhoea, gastric problems, bed sore etc.

Piperine, an alkaloid obtained from black pepper, showed a dose dependent inhibition of TNF $\alpha$, IL-1 $\beta$, IL-6 and PGE2 production from BV-2 microglial cells at a dose of 25$100 \mu \mathrm{g} / \mathrm{ml}$. This reduction was due to inhibition in $\mathrm{NF}-\kappa \beta$ signalling pathway and upregulation of nuclear factor E2 related factor 2 (Nrf-2) and haem oxygenase-1(HO1) pathway 19 .

Piperine brought down levels of NO, TNF- $\alpha$, IL-1 $\beta$, PGE2 along with the increase of IL10. It upregulated the antioxidant enzymes like glutathione (GSH), catalase and superoxide dismutase (SOD), reduced thiobarbituric acid reactive substances (TBARS), myeloperoxidase (MPO) and elastase activity along with the reduction in arthritic parameters as confirmed by histopathological studies such as decrease of cartilage erosion, absence of mononuclear infiltration in synovium etc $\mathbf{2 0}$.

\section{CONCLUSION}

In the current study, it was observed that both phases of the carrageenan-induced hind paw edema were significantly reduced by pretreatment of rats with some spices, due to decrease in serum levels of pro-inflammatory parameters like protein Creactive, neutophil, monocyte and eosinophil cells. The results obtained show that the common spices like ginger, cumin etc. possess antiinflammatory activity.

Consumption of spices in our daily life is associated with various health benefits, reduction of inflammation being one of them.

\section{REFERENCES}

1. WHO, Traditional Medicine Strategy 2002- 2005. WHO, Geneva, Switzerland.http://www.

wpro.who.int/health_technology/book_who_ traditional_medicine_strategy_2002_2005.pdf

2. Rafieian-Kopaei M. Medicinal plants and the human needs. Journal of HerbMed Pharmacology., 2002; 1:1:1-2.

3. Sherwood ER and Toliver-Kinsky T. Mechanisms of the inflammatory response. Best Pract Res Clin Anaesthesiol., 2002; 18:3:385-405.

4. Winter C. A. Risley E. A. and Nuss G. W. Carrageenan-induced edema in the hind paw of rat as an assay for anti-inflammatory activity. Proceedings of the Society for Experimental Biology and Medicine. 1962; 111:544- 547.

5. Jia Z, Tang M, Wu J. The determination of flavonoid contents in mulberry and their scavenging effects on superoxide radicals. Food chemistry, 1999; 64:555-559 
6. Singleton V.L., Orthofer R., Lamuela-Raventos R.M. Analysis of total phenols and other oxidant substrates and antioxidants by means of Folin-Ciocalteu reagent. Methods Enzymol; 1999; 299:152-178

7. Huang GJ, Huang SS, Lin SS et al., "Analgesic effects and the mechanisms of anti-inflammation of ergostatrien- $3 \beta$ - ol from antrodia camphorata submerged whole broth in mice," Journal of Agricultural and Food Chemistry, 2010; 58, no. 12, pp. 74457452

8. Helenius I. Lumme A. and Haahtela T. Asthma, airway inflammation and treatment in elite athletes. Sports Medicine., 2005 ; 35:7:565- 574

9. Huang GJ, Huang SS, Lin SS et al., "Analgesic effects and the mechanisms of anti-inflammation of ergostatrien- $3 \beta$ - ol from antrodia camphorata submerged whole broth in mice," Journal of Agricultural and Food Chemistry, 2010; 58, no. 12, pp. 74457452

10. Gurib-Fakim A, Medicinal plants: Traditions of yesterday, and drugs of tomorrow. Molecular Aspects of Medicine. 2006; 27:193.

11. Sosa S, Balick MJ, Arvigo R, Esposito RG, Pizza C, Altinier G, et al. Screening of the topical anti-inflammatory activity of some Central American plants. J Ethnopharmacol 2002; 81:211-5.

12. Arif T, Bhosale JD, Kumar N, Mandal TK, Bendre RS, Lavekar GS, et al. Natural products - antifungal agents derived from plants. J Asian Nat Prod Res 2009; 11:621-38.

13. Libby, P. Inflammatory mechanisms: the molecular basis of inflammation and disease. Nutr Rev., 2007; 65: 140-6
14. Panahi, Y., Hosseini, M. S., Khalili, N., Naimi, E., Simental-Mendía, L. E., Majeed, M., Sahebkar, A. Effects of curcumin on serum cytokine concentrations in subjects with metabolic syndrome: A post-hoc analysis of a randomized controlled trial. Biomedicine \& Pharmacotherapy, 2006; 82:578- 582.

15. Edwards, R. L., Luis, P. B., Varuzza, P. V., Joseph, A. I., Presley, S. H., Chaturvedi, R., Schneider, C. The anti-inflammatory activity of curcumin is mediated by its oxidative metabolites. Journal of Biological Chemistry, 2017; 292(52):21243-21252.

16. Bhat S. P., Rizvi W., Kumar A. Effect of Cuminum cyminum L. seed extracts on pain and inflammation. Journal of Natural Remedies, 2014; 14(2):186-192.

17. Ezzat S.M., Ezzat M.I., Okba M.M., Menze E.T., Abdel-Naim A.B. The hidden mechanism beyond ginger ( Zingiber officinale Rosc.) potent in vivo and in vitro anti-in Journal of Ethnopharmacology, 2018; 214:113-123.

18. Joseph T.M., Mahapatra D.K. InSilico Molecular Docking of Cuminaldehyde and its Bioconverted Ligands as Lipoxygenase and Cyclooxygenase-2 Inhibitors. Inventi Impact: Molecular Modeling, 2017; 118-121.

19. Wang-sheng C., Jie A., Jian-jun L., Lan H., Zengbao X., Chang-qing L. Piperine attenuates lipopolysaccharide (LPS)-induced inflammatory responses in BV2 microglia. International Immunopharmacology, 2017; 42:44-48.

20. Umar S., Sarwar A.H.M.G., Umar K., Ahmad N., Sajad M., Ahmad S., Katiyar C.K., Khan H.A. Piperine ameliorates oxidative stress, inflammation and histological outcome in collagen induced arthritis. Cellular Immunology, 2013; 284(1-2):51-59. 